\title{
Primary antibiotic resistance and associated mechanisms in Helicobacter pylori isolates from Senegalese patients
}

\author{
Abdoulaye Seck ${ }^{1}$, Christophe Burucoa ${ }^{2}$, Daouda Dia ${ }^{3}$, Mouhamadou Mbengue $^{3}$, Manuella Onambele ${ }^{1}$ \\ Josette Raymond ${ }^{4}$ and Sebastien Breurec ${ }^{1 *}$
}

\begin{abstract}
Background: Antibiotic combination therapy for Helicobacter pylori eradication must be adapted to local resistance patterns, but the epidemiology of $\mathrm{H}$. pylori resistance to antibiotics is poorly documented in Africa. The aim was to determine the antibiotic resistance rates, as well as the associated molecular mechanisms, of strains isolated in Dakar, Senegal.

Methods: One hundred and eight H. pylori strains were isolated between 2007 and 2009 from 108 patients presenting with upper abdominal pain to the Gastroenterology Department of Le Dantec Hospital. Antimicrobial susceptibility testing was performed for amoxicillin, clarithromycin, metronidazole, levofloxacin and tetracyclin using the E-test method. Mutations in the $23 \mathrm{~S}$ rRNA gene of clarithromycin-resistant strains and in gyrA and gyrB of levofloxacin-resistant strains were investigated.

Results: Isolates were characterized by no resistance to amoxicillin (0\%), tetracycline (0\%), and very low rate of resistance to clarithromycin (1\%), but a high rate of resistance to metronidazole (85\%). The clarithromycin-resistant strain displayed the A2143G mutation. A worrying rate of levofloxacin resistance was detected (15\%). N87I and D91N were the most common mutations in the quinolone-resistance-determining region of gyrA.

Conclusions: The first-line empirical regimen for H. pylori eradication in Senegal should include clarithromycin. Increasing rates of fluoroquinolone resistance detected should discourage the use of levofloxacin-containing regimens without prior antimicrobial susceptibility testing.
\end{abstract}

Keywords: Helicobacter pylori, Levofloxacin, Clarithromycin, Antibiotic resistance, Senegal

\section{Background}

Helicobacter pylori is associated with severe gastroduodenal disorders, including peptic ulcer disease, gastric adenocarcinoma, and gastric mucosa-associated lymphoid tissue lymphoma [1]. About 15\% of infected people will develop a peptic ulcer and 1-3\% a gastric malignancy during their lifetime. All guidelines worldwide recommend the eradication of $H$. pylori in symptomatic patients [2]. This treatment commonly consists of tripleagent therapy with a double-dose proton pump inhibitor (PPI) and two antibiotics chosen from amoxicillin,

\footnotetext{
*Correspondence: sbreurec@gmail.com

${ }^{1}$ Institut Pasteur, Unité de Biologie Médicale et Environnementale, 36 avenue pasteur, Dakar BP220, Senegal

Full list of author information is available at the end of the article
}

clarithromycin and metronidazole, for 7 to 14 days, yielding an eradication rate ranging from $70 \%$ to $80 \%$. Antibiotic resistance is the main cause of treatment failure. In particular, clarithromycin resistance can lead to a $70 \%$ decrease in efficacy [3]. Bismuth-containing fourdrug regimens or, if the latter are unavailable, sequential treatment or a non-bismuth four-drug regimen, is recommended for first-line empirical treatment in areas of high clarithromycin resistance. Levofloxacin-containing triple therapy should be preferred when these treatments fail [2]. Clarithromycin resistance is mainly due to point mutations in the $23 \mathrm{~S}$ ribosomal RNA (rRNA) gene. $\mathrm{A} 2143 \mathrm{G}$ and $\mathrm{A} 2142 \mathrm{G}$ are the most frequent mutations [4]. Resistance to quinolones is mainly due to mutations in the quinolone-resistance-determining region (QRDR) 
of the gyrA gene, coding for the A subunit of the DNA gyrase, at codons $86,87,88$ and 91 [3]. Very few data are available on $H$. pylori resistance to antibiotics in Africa [5-9]. Here we examined the prevalence of $H$. pylori resistance to antibiotics, and the associated molecular mechanisms, in symptomatic African patients in Dakar (Senegal).

\section{Methods}

\section{Study population}

A total of $108 \mathrm{H}$. pylori strains were isolated between 2007 and 2009 from 108 patients presenting with upper abdominal pain to the Gastroenterology Department of Le Dantec Hospital (Dakar, Senegal). Median age was 42.0 years (mean 45.3 years; interquartile range (IQR) $31.0-56.6$ years; range, $18-93$ years), and $55 \%$ of the patients $(n=59)$ were males. The predominant ethnic groups were Wolof (37\%), Fulani (16\%), and Serer (14\%), in keeping with the ethnic distribution in Senegal. On the basis of endoscopic findings, 30 patients had gastritis only, 63 had ulcerated lesions, and 15 had suspicion of neoplasia. All cases of suspected neoplasia were histologically confirmed as gastric cancer.

No patient had previously received anti-H. pylori therapy. Three biopsy samples were taken from the antrum and three from the fundus during upper gastrointestinal endoscopy. One biopsy sample from each site was cultured for H. pylori isolation, and the other four were fixed and processed for histological analysis. All endoscopes and accessory devices were decontaminated after every endoscopy, according to local written procedures. On the basis of endoscopic findings, patients were classified as having gastritis only, ulcerated lesion, or suspicion of neoplasia. Written informed consent was obtained from all the patients and the study protocol was approved by the Senegalese national ethics committee.

\section{Histology}

Histopathological diagnoses were performed according to the updated Sydney System [10], and to the Vienna classification for dysplasia [11].

\section{H. Pylori culture and antimicrobial susceptibility testing}

H. pylori culture was performed using Columbia agar plates with $10 \%(\mathrm{v} / \mathrm{v})$ defibrinated horse blood and an $H$. pylori selective antibiotic supplement (Oxoid, Basingstoke, UK) containing vancomycin $(10 \mathrm{mg} / \mathrm{L})$, cefsulodin $(5 \mathrm{mg} / \mathrm{L})$, trimethoprim $(5 \mathrm{mg} / \mathrm{L})$ and amphotericin B (5 $\mathrm{mg} / \mathrm{L})$. The plates were incubated for up to 10 days at $37^{\circ} \mathrm{C}$ in microaerophilic conditions (GENbag, Biomerieux). H. pylori was identified by colony and microscopic morphology, and by positive urease, catalase and oxidase tests. Antibiotic susceptibility was determined from a mixture of colonies from antrum and fundus samples with the E-test method (Biomérieux, Marcy l'Etoile, France) using Mueller-Hinton agar supplemented with $10 \%$ horse blood as previously described [12]. According to CLSI breakpoints [13], the resistance breakpoints were $0.5 \mathrm{mg} / \mathrm{L}$ for amoxicillin (EUCAST [14], $\geq 0.12$ $\mathrm{mg} / \mathrm{L}$ ), $1 \mathrm{mg} / \mathrm{L}$ for clarithromycin (EUCAST, $\geq 0.5 \mathrm{mg} /$ L), $2 \mathrm{mg} / \mathrm{L}$ for tetracycline (EUCAST, $\geq 1 \mathrm{mg} / \mathrm{L}$ ), $1 \mathrm{mg} / \mathrm{L}$ for levofloxacin (similar to the EUCAST value), and 8 $\mathrm{mg} / \mathrm{L}$ for metronidazole (similar to the EUCAST value).

\section{DNA extraction and mutation analysis of the $23 \mathrm{~S}$ rRNA, gyrA and gyrB genes}

Genomic DNA was extracted with the QIAmp kit (Qiagen, Courtaboeuf, France). The QRDR region of gyrA was sequenced using primers gyrA5 and gyrA2 in levofloxacin-resistant strains [4]. If no mutation was detected, the full-length $\operatorname{gyr} A$ and $\operatorname{gyr} B$ genes were sequenced as previously described [4] and were compared with the sequences from five randomly selected levofloxacin-sensitive isolates. Point mutations in the 23S rRNA gene were investigated by using Scorpion PCR in strains resistant to clarithromycin [12].

\section{Statistical analysis}

The chi-square test for trend was used to compare rates of resistance to antibiotics during the study period. $P$ values of $\leq 0.05$ were considered statistically significant. All analyses were performed by using STATA 12.0 (Stata Corporation, College Station, Tex.).

\section{Results}

\section{Patients and antibiotic susceptibility testing}

One hundred eight $H$. pylori isolates were cultured from gastric biopsy samples obtained from volunteers during gastroduodenal endoscopy at Le Dantec Hospital (Dakar, Senegal) between 2007 and 2009.

According to EUCAST and CLSI breakpoints, all isolates tested were susceptible to amoxicillin (MIC range, $<0.016-0.047 \mathrm{mg} / \mathrm{L}$ ), tetracycline (MIC range, <0.016$0.75 \mathrm{mg} / \mathrm{L}$ ) and clarithromycin (MIC range, $<0.016-0.47$ $\mathrm{mg} / \mathrm{L}$ ), except for one clarithromycin-resistant strain (MIC $>256 \mathrm{mg} / \mathrm{l}$ ). The isolates were characterized by high rates of resistance to metronidazole (MIC range, $<0.016$ $>256 \mathrm{mg} / \mathrm{L})(85 \%, \mathrm{n}=92)$ and intermediate rates of susceptibility to levofloxacin ((MIC range, $<0.002->32 \mathrm{mg}$ / L) $(85 \%, \mathrm{n}=92)$ (Table 1). The clarithromycin-resistant strain was resistant to both levofloxacin (MIC $>32 \mathrm{mg} / \mathrm{L}$ ) and metronidazole (MIC $>256 \mathrm{mg} / \mathrm{L})$. Twelve of the 16 levofloxacin-resistant strains were also resistant to metronidazole. No significant difference in the prevalence of resistance to antibiotics was observed during the study period $(\mathrm{P}>0.5)$. 
Table 1 Resistance to antibiotics of $\boldsymbol{H}$. pylori isolates in Dakar, Senegal, from 2007 to 2009

\begin{tabular}{lccc}
\hline & $\mathbf{n ~ ( \% )}$ & \multicolumn{2}{c}{ MIC (mg/L) } \\
\cline { 3 - 4 } & & $<0.016$ & Range \\
\hline Amoxicillin & 0 & $<0.016$ & $<0.016-0.047$ \\
Tetracycline & 0 & 0,125 & $<0.002->32$ \\
Levofloxacin & $16(15)$ & $>256$ & $<0.016->256$ \\
Metronidazole & $92(85)$ & $<0.016$ & $<0.016->256$ \\
Clarithromycin & $1(1)$ & &
\end{tabular}

\section{Mutation of the 23S rRNA gene in the clarithromycin- resistant strain and of gyrA and gyrB in levofloxacin- resistant strains}

Only one strain was resistant to clarithromycin. Resistance was due to a point mutation at nucleotide position 2143 (A2143G) of the 23S rRNA gene. Among the 16 levofloxacin-resistant strains, 13 harbored a specific mutation in the QRDR of the gyrA gene, previously reported to confer resistance to fluoroquinolones. The amino acid positions concerned were 87 and 91: N87I, $\mathrm{n}=7$ (MICs $>32 \mathrm{mg} / \mathrm{l}) ; \mathrm{D} 91 \mathrm{~N}, \mathrm{n}=4$ (MIC range, 4-16 mg/ l); D91G, n=1 (MIC=2 mg/l); D91Y, n=1 (MIC>32 mg/l). As three strains with MICs of $8 \mathrm{mg} / \mathrm{l}$ displayed no mutations in the QRDR of $g y r A$, the entire $g y r A$ and $g y r B$ genes of these strains were sequenced. No mutation was detected.

\section{Discussion}

Antibiotic resistance is the most important factor responsible for the declining success rate of $H$. pylori eradication therapy. Surveillance of $H$. pylori antibiotic resistance is mandatory in order to adapt the antibiotic combination to local resistance patterns.

The rates of $H$. pylori resistance to amoxicillin (0\%) and metronidazole (85\%) observed in Senegal were in keeping with those reported in this country in 19992000 (0\% and 90\%, respectively) [8]. In contrast, resistance to levofloxacin rose from $0 \%$ in 1999-2000 to $15 \%$ in 2007-2008, mirroring the situation in several European and Asian countries, with increases from 3\% in 1999 to $15 \%$ in 2004 in France, from $11 \%$ in 2003 to $22 \%$ in 2005 in Germany, from 3\% in 1998 to $12 \%$ in 2003 in Taiwan, and from $0 \%$ in 1987 to 33\% in 2003 in South Korea [15-19]. This probably reflects the increasing use of quinolones in these countries [20,21], highlighting the importance of appropriate use of this class of antibiotics to limit the development of antimicrobial resistance. Interestingly, a significant increase in ciprofloxacin resistance has also been observed in Escherichia coli isolates from Senegalese patients with communityacquired urinary tract infections (10\% in 2004, $22 \%$ in 2006) [22].
The lack of resistance to amoxicillin and tetracycline in this study indicates that $H$. pylori resistance to these agents is probably exceptional (0 to $1.3 \%$ ) and low (0 to $4.4 \%)$, respectively, whatever the continent [21,23]. The high prevalence of resistance to these antibiotics observed in some developing and emerging countries probably reflects inadequate laboratory facilities [5-7,9] (e.g. 6\% in Ethiopia, 6.6\% in Bangladesh, 39.0\% in Brazil, $59 \%$ in Iran for resistance to amoxicillin; $9.0 \%$ in Brazil, $15.0 \%$ in Bangladesh, $27.0 \%$ in Chile for resistance to tetracyclin). In our study, only one strain was resistant to clarithromycin (MIC>256 mg/l), likely reflecting low macrolide consumption, although no data on antibiotic consumption for clarithromycin but also erythromycin and azithromycin are available for Senegal. This resistance was due to a point mutation at nucleotide position 2143 (A2143G) of the 23S rRNA gene, a well-known mutation described worldwide. Resistance to clarithromycin is increasing in most countries in Central, Western and Southern Europe, as well as in East Asia, and has now reached more than $20 \%$ in these areas. Clarithromycin-containing regimens should thus be recommended for first-line empirical H. pylori eradication therapy.

The prevalence of resistance to levofloxacin was $15 \%$ in Senegal. In the 16 levofloxacin-resistant strains, N87I and D91N were the most common mutations in the QRDR region of gyrA. The major mutation (N87I) has been detected sporadically worldwide [16], indicating that local founder effects have resulted in local propagation of resistant clones. D91N is a well-known mutation detected worldwide [4]. As three strains with levofloxacin MICs of $8 \mathrm{mg} / \mathrm{l}$ displayed no mutations in the QRDR of $g y r A$, we sequenced the entire $g y r A$ and $g y r B$ genes of these strains but found no mutations. This points to the presence of another mechanism such as reduced drug accumulation [4]. The Maastricht IV/Florence Consensus Report recommends that empirical use of levofloxacin should be abandoned when the prevalence of resistance reaches 15-20\% [2]. Levofloxacin-containing therapy should therefore only be used in Senegal if compatible with the antimicrobial resistance pattern of the strain.

The worldwide prevalence of resistance to metronidazole ranges from $20-40 \%$ in Europe and the USA, to 50-80\% in developing countries, Iran, India and Egypt displaying the highest rates of resistance (80 to $100 \%$ ) $[6,21,24,25]$. Metronidazole is used extensively to treat parasitic diseases in tropical countries, which probably explains the higher prevalence of resistance to this drug. Although standard metronidazole susceptibility testing lacks reproducibility, trends of low, medium, or high prevalence rates observed at a population level seem real. Then, metronidazole-containing triple therapy should not 
be recommended for first-line empirical $H$. pylori eradication therapy. It should be used within bismuth-based quadruple regimen [26] or sequential treatment for 14 days [27].

\section{Conclusions}

Even though our findings may not be representative of the overall situation, it should be noted that the study took place in one of the main tertiary hospitals in Senegal, with a large geographical origin of the patients attending the study health facility. The data reported here are particularly important, given the difficulty of carrying out such studies in countries with inadequate healthcare systems and the need to choose antibiotic combinations for $H$. pylori eradication according to local resistance patterns. Clarithromycincontaining regimens should be recommended for first-line empirical $H$. pylori eradication therapy. Increasing rates of fluoroquinolone resistance detected in Senegal should discourage the use of levofloxacin-containing regimens without prior antimicrobial susceptibility testing. N87I and D91N were the most common mutations in the H. pylori gyrA QRDR.

\section{Abbreviations}

PPI: Proton pump inhibitor; rRNA: 23 S ribosomal RNA; QRDR: Quinoloneresistance-determining region.

\section{Competing interests}

The authors have no competing interests to declare.

\section{Authors' contributions}

Conceived and designed the experiments: AS, CB, MM, JR; SB. Performed the experiments: $A S, C B, M O, S B$. Analyzed the data: $A S, C B, M O, J R, S B$. Contributed reagents/materials/analysis tools: $A S, C B, D D, M M, S B$. Wrote the paper: AS, SB. Found funding: SB, JR. All authors read and approved the final manuscript.

\section{Acknowledgments}

We thank Fatou Bintou Dieye and Cheikh Fall (Institut Pasteur, Dakar, Senegal) for their technical assistance, and also the clinicians involved in this study. This study was supported by a grant from Institut Pasteur (ACIP Helicobacter pylori)

\section{Author details}

'Institut Pasteur, Unité de Biologie Médicale et Environnementale, 36 avenue pasteur, Dakar BP220, Senegal. ${ }^{2}$ EA 4331 LITEC, Université de Poitiers, CHU de Poitiers, Laboratoire de Bactériologie-Hygiène, 2, rue de la Miletrie, Poitiers BP 577, 86021, France. ${ }^{3}$ Département de Gastro-entérologie, Centre Hospitalier Le Dantec, 30 avenue Pasteur, BP3001, Dakar, Senegal. ${ }^{4}$ Unité Postulante de Pathogénèse de Helicobacter, Institut Pasteur, 25-28 rue du Docteur Roux, 75724, Paris Cedex 15, France.

Received: 27 October 2012 Accepted: 5 January 2013

Published: 8 January 2013

\section{References}

1. Parsonnet J, Friedman GD, Vandersteen DP, Chang Y, Vogelman JH, Orentreich N, Sibley RK: Helicobacter pylori infection and the risk of gastric carcinoma. N Engl J Med 1991, 325:1127-1131.

2. Malfertheiner P, Megraud F, O'Morain CA, Atherton J, Axon AT, Bazzoli F, Gensini GF, Gisbert JP, Graham DY, Rokkas T, El-Omar EM, Kuipers EJ: Management of Helicobacter pylori infection-the Maastricht IV/ Florence Consensus Report. Gut 2012, 61:646-664.
3. Megraud F: Helicobacter pylori and antibiotic resistance. Gut 2007, 56:1502.

4. Garcia M, Raymond J, Garnier M, Cremniter J, Burucoa C: Distribution of spontaneous gyrA mutations in 97 fluoroquinolone-resistant Helicobacter pylori isolates collected in France. Antimicrob Agents Chemother 2012, 56:550-551.

5. Godoy AP, Ribeiro ML, Benvengo YH, Vitiello L, Miranda Mde C, Mendonca S, Pedrazzoli J Jr: Analysis of antimicrobial susceptibility and virulence factors in Helicobacter pylori clinical isolates. BMC Gastroenterol 2003, 3:20.

6. Nahar S, Mukhopadhyay AK, Khan R, Ahmad MM, Datta S, Chattopadhyay S, Dhar SC, Sarker SA, Engstrand L, Berg DE, Nair GB, Rahman M: Antimicrobial susceptibility of Helicobacter pylori strains isolated in Bangladesh. J Clin Microbiol 2004, 42:4856-4858.

7. Aboderin OA, Abdu AR, Odetoyin B, Okeke IN, Lawal OO, Ndububa DA, Agbakwuru AE, Lamikanra A: Antibiotic resistance of Helicobacter pylori from patients in lle-lfe, South-west, Nigeria. Afr Health Sci 2007, 7:143-147.

8. Seck A, Mbengue M, Gassama-Sow A, Diouf L, Ka MM, Boye CS: Antibiotic susceptibility of Helicobacter pylori isolates in Dakar, Senegal. I Infect Dev Ctries 2009, 3:137-140.

9. Ndip RN, Malange Takang AE, Ojongokpoko JE, Luma HN, Malongue A, Akoachere JF, Ndip LM, MacMillan M, Weaver LT: Helicobacter pylori isolates recovered from gastric biopsies of patients with gastroduodenal pathologies in Cameroon: current status of antibiogram. Trop Med Int Health 2008, 13:848-854.

10. Price $A B$ : Classification of gastritis-yesterday, today and tomorrow. Verhandlungen der Deutschen Gesellschaft fur Pathologie 1999, 83:52-55.

11. Schlemper RJ, Riddell RH, Kato Y, Borchard F, Cooper HS, Dawsey SM, Dixon MF, Fenoglio-Preiser CM, Flejou JF, Geboes K, Hattori T, Hirota T, Itabashi M, Iwafuchi M, Iwashita A, Kim YI, Kirchner T, Klimpfinger M, Koike M, Lauwers GY, Lewin KJ, Oberhuber G, Offner F, Price AB, Rubio CA, Shimizu M, Shimoda T, Sipponen P, Solcia E, Stolte M, et al: The Vienna classification of gastrointestinal epithelial neoplasia. Gut 2000, 47:251-255.

12. Ben Mansour K, Burucoa C, Zribi M, Masmoudi A, Karoui S, Kallel L, Chouaib S, Matri S, Fekih M, Zarrouk S, Labbene M, Boubaker J, Cheikh I, Hriz MB, Siala N, Ayadi A, Filali A, Mami NB, Najjar T, Maherzi A, Sfar MT, Fendri C: Primary resistance to clarithromycin, metronidazole and amoxicillin of Helicobacter pylori isolated from Tunisian patients with peptic ulcers and gastritis: a prospective multicentre study. Ann Clin Microbiol Antimicrob 2010, 9:22

13. Clinical and Laboratory Standards Institute: Performance standards for antimicrobial susceptibility testing; twentieth informational supplement, CLSI document. Wayne, PA: Clinical and Laboratory Standards Institute; 2012: M100-S22.

14. European Committee on Antimicrobial Susceptibility Testing: EUCAST Disk diffusion manual 2012. http://www.eucast.org/eucast_susceptibility_testing/ disk_diffusion_methodology.

15. Glocker E, Stueger HP, Kist M: Quinolone resistance in Helicobacter pylori isolates in Germany. Antimicrob Agents Chemother 2007, 51:346-349.

16. Hung KH, Sheu BS, Chang WL, Wu HM, Liu CC, Wu JJ: Prevalence of primary fluoroquinolone resistance among clinical isolates of Helicobacter pylori at a University Hospital in Southern Taiwan. Helicobacter 2009, 14:61-65.

17. Kim JM, Kim JS, Kim N, Jung HC, Song IS: Distribution of fluoroquinolone MICs in Helicobacter pylori strains from Korean patients. J Antimicrob Chemother 2005, 56:965-967.

18. Tankovic J, Lascols C, Sculo Q, Petit JC, Soussy CJ: Single and double mutations in gyrA but not in gyrB are associated with low- and highlevel fluoroquinolone resistance in Helicobacter pylori. Antimicrob Agents Chemother 2003, 47:3942-3944.

19. Cattoir V, Nectoux J, Lascols C, Deforges L, Delchier JC, Megraud F, Soussy CJ, Cambau E: Update on fluoroquinolone resistance in Helicobacter pylori: new mutations leading to resistance and first description of a gyrA polymorphism associated with hypersusceptibility. Int I Antimicrob Agents 2007, 29:389-396.

20. Cuadrado-Lavin A, Salcines-Caviedes JR, Carrascosa MF, Mellado P, Monteagudo I, Llorca J, Cobo M, Campos MR, Ayestaran B, Fernandez-Pousa A, GonzalezColominas E: Antimicrobial susceptibility of Helicobacter pylori to six antibiotics currently used in Spain. J Antimicrob Chemother 2012, 67:170-173.

21. Boyanova L, Mitov I: Geographic map and evolution of primary Helicobacter pylori resistance to antibacterial agents. Expert Rev Anti Infect Ther 2010, 8:59-70 
22. Sire JM, Nabeth P, Perrier-Gros-Claude JD, Bahsoun I, Siby T, Macondo EA, Gaye-Diallo A, Guyomard S, Seck A, Breurec S, Garin B: Antimicrobial resistance in outpatient Escherichia coli urinary isolates in Dakar, Senegal. $J$ Infect Dev Ctries 2007, 1:263-268.

23. De Francesco V, Giorgio F, Hassan C, Manes G, Vannella L, Panella C, lerardi E, Zullo A: Worldwide Helicobacter pylori antibiotic resistance: a systematic review. J Gastrointestin Liver Dis 2010, 19:409-414.

24. Sherif M, Mohran Z, Fathy H, Rockabrand DM, Rozmajzl PJ, Frenck RW: Universal high-level primary metronidazole resistance in Helicobacter pylori isolated from children in Egypt. J Clin Microbiol 2004, 42:4832-4834

25. Asrat D, Kassa E, Mengistu Y, Nilsson I, Wadstrom T: Antimicrobial susceptibility pattern of Helicobacter pylori strains isolated from adult dyspeptic patients in Tikur Anbassa University Hospital, Addis Ababa, Ethiopia. Ethiop Med J 2004, 42:79-85.

26. Gisbert JP: Rescue Therapy for Helicobacter pylori Infection 2012. Gastroenterol Res Pract 2012, in press.

27. Liou JM, Chen CC, Chen MJ, Chang CY, Fang YJ, Lee JY, Hsu SJ, Luo JC, Chang WH, Hsu YC, Tseng CH, Tseng PH, Wang HP, Yang UC, Shun CT, Lin $J T$, Lee YC, Wu MS: Sequential versus triple therapy for the first-line treatment of Helicobacter pylori: a multicentre, open-label, randomised trial. Lancet 2012, in press.

doi:10.1186/1476-0711-12-3

Cite this article as: Seck et al:: Primary antibiotic resistance and associated mechanisms in Helicobacter pylori isolates from Senegalese patients. Annals of Clinical Microbiology and Antimicrobials 2013 12:3.

\section{Submit your next manuscript to BioMed Central and take full advantage of:}

- Convenient online submission

- Thorough peer review

- No space constraints or color figure charges

- Immediate publication on acceptance

- Inclusion in PubMed, CAS, Scopus and Google Scholar

- Research which is freely available for redistribution 